\title{
Erratum to: Asparagine synthetase deficiency-report of a novel mutation and review of literature
}

\author{
Neerja Gupta ${ }^{1}$ - Vishal Vishnu Tewari ${ }^{2}$ - Manoj Kumar ${ }^{3}$. Nitika Langeh ${ }^{1}$. \\ Aditi Gupta ${ }^{1}$ - Pallavi Mishra ${ }^{1}$ Punit Kaur $^{3}$. Vedam Ramprasad ${ }^{4}$. \\ Sakthivel Murugan ${ }^{4} \cdot$ Reema Kumar $^{5} \cdot$ Manisha Jana $^{6} \cdot$ Madhulika Kabra $^{1}$
}

Published online: 5 September 2017

(C) Springer Science+Business Media, LLC 2017

Erratum to: Metab Brain Dis (2017)

https://doi.org/10.1007/s11011-017-0073-6

In the original publication of the article, affiliations of Vedam Ramprasad, Sakthivel Murugan and Reema Kumar were incorrectly listed. Their correct affiliations are provided in this erratum.

The online version of the original article can be found at https://doi.org/ 10.1007/s11011-017-0073-6

Neerja Gupta

neerja17aiims@gmail.com

1 Division of Genetics, Department of Pediatrics, All India Institute of Medical Sciences, New Delhi 110029, India

2 Department of Pediatrics, Army Hospital (Referral \& Research), New Delhi, India

3 Department of Biophysics, All India Institute of Medical Sciences, New Delhi 110029, India

4 MedGenome Labs, Bangalore, India

5 Department of Obstetrics \& Gynaecology, Army Hospital (Referral \& Research), New Delhi, India

6 Department of Radiology, All India Institute of Medical Sciences, New Delhi 110029, India 